DOI: $10.29303 /$ jrpb.v8i2.175

ISSN 2301-8119, e-ISSN 2443-1354

Tersedia online di http://jrpb.unram.ac.id/

\title{
IMPLEMENTASI PENGELOLAAN IRIGASI BERBASIS LIMA PILAR MODERNISASI IRIGASI DI BATANG ANAI SUMATRA BARAT
}

\author{
Implementation of Irrigation Management Based on Five Pillars \\ of Irrigation Modernization in Batang Anai West Sumatra
}

\author{
Suci Ristiyana ${ }^{1, *}$, Tri Wahyu Saputra ${ }^{1}$, Ika Purnamasari ${ }^{1}$, Sigit Supadmo Arif $^{2}$ \\ ${ }^{1}$ Jurusan Agroteknologi, Fakultas Pertanian, Universitas Jember \\ Jl. Kalimantan No. 37, Kampus Tegalboto, Jember 68121, Indonesia \\ ${ }^{2}$ Jurusan Teknik Pertanian dan Biosistem, Fakultas Teknologi Pertanian, \\ Universitas Gadjah Mada \\ Jl. Sosio Yustisia, Bulaksumur, Yogyakarta 55281, Indonesia \\ Email*): suciristi@unej.ac.id \\ Diterima: Juli 2020 \\ Disetujui: September 2020
}

\begin{abstract}
The purpose of this research was to determine the irrigation modernization policy strategy positioning at Batang Anai Irrigation System (IS). The irrigation modernization policy determined by short-term and long-term. The data processed with AHP method and policies taken based on SWOT (Strengths Weaknesses Opportunities Threats) method. The results of this study indicate that the Batang Anai IA strategy for irrigation management systems included in the turn around quadrant III (Opportunities - Weaknesses). Whereas the pillars of government institutions and human resources included in the SWOT Defensive Strategy Quadrant (Weaknesses - Threats). The irrigation modernization policy at Batang Anai begins with the accuracy and speed of response to damage on the canal in accordance with the applicable operation and maintenance. In addition, the existing operation and maintenance funds must also be adjusted to the real need for operation and maintenance.
\end{abstract}

Keywords: irrigation; policy; modernization of irrigation

\begin{abstract}
ABSTRAK
Tujuan dari penelitian ini adalah menentukan letak strategi kebijakan modernisasi irigasi, kebijakan yang diambil berada di Daerah Irigasi Batang Anai. Penyusunan kebijakan modernisasi irigasi ditentukan dengan tempo waktu jangka pendek dan jangka panjang. Data yang ada diolah dengan metode Analytical Hierarchy Process (AHP) dan kebijakan yang diambil menggunakan metode SWOT (Strengths Weaknesses Opportunities Threats). Hasil penelitian ini menunjukan bahwa Daerah Irigasi Batang Anai masuk dalam strategi turn around kuadran III (Opportunities - Weaknesses) untuk sistem pengelolaan irigasi. Sedangkan untuk pilar institusi pemerintah dan sumber daya manusia masuk dalam Strategi defensif kuadran IV (Weaknesses - Threats) SWOT. Kebijakan modernisasi irigasi Daerah Irigasi Batang Anai dimulai dengan ketepatan dan kecepatan respon terhadap kerusakan saluran sesuai dengan
\end{abstract}


operasi dan pemeliharaan yang berlaku. Selain itu, dana operasi dan pemeliharaan yang ada juga harus disesuaikan dengan angka kebutuhan nyata operasi dan pemeliharaan.

Kata kunci: irigasi; kebijakan; modernisasi irigasi

\section{PENDAHULUAN}

\section{Latar Belakang}

Air merupakan suatu kebutuhan utama bagi manusia di dunia. Air juga sangat diperlukan untuk kegiatan industri, perikanan, pertanian dan usaha yang lain. Namun dalam kenyataannya manusia sering tidak hati-hati dalam pemakaiannya, sehingga dalam pemanfaatan tersebut diperlukan upaya untuk menjaga keseimbangan antara ketersediaan dan kebutuhan air melalui pengembangan, pelestarian, perbaikan dan perlindungan. Pemanfaatan air terkait pertanian bertujuan untuk memenuhi kebutuhan pangan serta pengembangan daerah atau wilayah (Priyonugroho, 2014).

Ketahanan air sangat vital dalam kehidupan manusia, dan terkait erat dengan ketahanan pangan dan energi, sebagai nexus ketahanan air, pangan, dan energi (Head \& Cammerman, 2010), serta memiliki peranan penting dalam adaptasi perubahan iklim (Rasul \& Sharma, 2016). Ketahanan air terkait erat dengan kondisi keseimbangan antara pendayagunaan sumber daya air untuk mendukung berbagai sektor kehidupan, dengan konservasi sumber daya air.

Irigasi sebagai salah satu komponen pendukung keberhasilan pembangunan pertanian mempunyai peran yang sangat penting. Keterbatasan anggaran yang dimiliki pemerintah mengakibatkan dana operasi dan pemeliharaan menjadi terbatas, sehingga dampaknya banyak kondisi teknis jaringan irigasi, baik secara fisik maupun fungsi menjadi terganggu. Hal ini dapat diatasi melalui kerja sama yang baik antara pemerintah dan masyarakat khususnya petani yang merasakan dampak secara langsung (Wiyono \& Wachyuni, et al, 2013).
Dalam Rencana Pembangunan Jangka Menengah Nasional (RPJMN) 2015-2019 disebutkan bahwa salah satu strategi dalam rangka peningkatan layanan irigasi adalah melalui pembentukan manajer irigasi sebagai pengelola pada satuan daerah irigasi. Pada program Integrated Participatory Development and Management Irrigation Project (IPDMIP) tentang Improvement of irrigation systems field management, disebutkan bahwa pembentukan Unit Pengelola Irigasi (Irrigation Management Unit/IMU) adalah untuk mencapai kinerja sistem irigasi berkelanjutan (Direktorat Irigasi dan Rawa, 2015).

Kebijakan pengelolaan irigasi yang selama ini hanya ditangani pemerintah pada awalnya dapat memberikan dampak yang cukup baik, hal ini dapat dilihat dengan tercapainya swasembada pangan, khususnya beras pada tahun 1984. Namun, sangat disayangkan bahwa keberhasilan tersebut tidak berkelanjutan karena fungsi prasarana irigasi, baik dari segi kuantitas, kualitas maupun fungsinya mengalami penurunan akibat jaringan irigasi banyak mengalami degradasi (Prasetijo, 2010)

Pengelolaan irigasi di jaringan utama oleh pemerintah dibedakan menurut arasnya berdasarkan pada luasan irigasi dan wilayah administratif. Pemerintah berwenang pada Daerah Irigasi (DI) dengan luasan lebih dari 3000 ha, DI lintas provinsi, DI lintas negara dan DI strategis nasional. DI dengan luas layanan 1000 ha -3000 ha dan lintas kabupaten/kota menjadi wewenang pemerintah provinsi, sedangkan DI dengan luas layanan di bawah 1000 ha dan dalam satu kabupaten/kota menjadi wewenang pemerintah kabupaten/kota tersebut (Murtiningrum \& Ristiana, et al, 2014).

Hal ini mendorong pemerintah untuk melakukan penyempurnaan sistem pengembangan dan pengelolaan irigasi menjadi sistem irigasi partisipatif yang lebih 
efektif, efisien, dan berkelanjutan (sustainable) atau disebut dengan istilah modernisasi irigasi, yang lebih menitikberatkan pada upaya meningkatkan efisiensi irigasi dan tingkat layanan. (Angguniko \& Hidayah, 2017)

Menurut FAO (1997), modernisasi irigasi adalah "a process of technical and managerial upgrading of irrigation schemes combined with institutional reforms, if required, with the objective to improve resource utilization (labor, water, economic, environmental) and water delivery service to farms". Modernisasi irigasi merupakan upaya mewujudkan sistem pengelolaan irigasi partisipatif berorientasi pada pemenuhan tingkat layanan irigasi secara efektif, efisien, dan berkelanjutan dalam rangka mendukung ketahanan pangan dan air melalui peningkatan keandalan penyediaan air, prasarana, pengelolaan irigasi, institusi pengelola, dan sumberdaya manusia (Arif \& Prabowo, et al., 2014).

Hasil keputusan untuk melakukan modernisasi irigasi tersebut telah diikuti oleh banyak negara, diantaranya: Malaysia melakukan pembangunan dam, stasiunstasiun pompa, pengembangan jalan inspeksi kanal dan jalan transportasi hasil panen serta peningkatan efisiensi (Martief \& Krisbandono, 2015); Vietnam membentuk Irrigation Modernization Frame (IMF) pada Red River Delta (RRD) yang merupakan manajemen berorientasi layanan agar tercipta efisiensi eksploitasi irigasi (Nam, 2016).

Modernisasi irigasi juga berbeda dengan rehabilitasi yang hanya menekankan pada aspek fisik saja. Dalam konsep modernisasi irigasi, selain menekankan pada aspek fisik, juga dilakukan peningkatan pada aspek kelembagaan pengelolaan dan sumberdaya manusianya, sehingga dapat memberikan pelayanan kepada petani (Hakim \& Suriadi, et al., 2012).

\section{Tujuan}

Tujuan penelitian ini adalah menentukan letak strategi kebijakan masingmasing pilar dalam kuadran SWOT dan menyusun kebijakan modernisasi irigasi yang ditentukan dengan tempo waktu jangka pendek dan jangka panjang.

\section{METODE PENELITIAN}

Alat dan Bahan
Data yang digunakan adalah data
primer dan data sekunder. Pengumpulan data
primer dilakukan dengan:
a. Wawancara menggunakan kuesioner
pada 3 pilar modernisasi irigasi, yaitu
pilar sumber daya manusia,
pengelolaan, dan institusi pemerintah
terhadap pengelola irigasi yang terdiri
dari BBWS (Balai Besar Wilayah
Sungai), Balai Provinsi, Dinas SDA
(Sumber Daya Air)/Pengairan, UPTD
(Unit Pelaksana Teknis Daerah) Dinas
SDA/Pengairan, Unit Pelaksana
Bendung/Waduk, dan petani
(IP3A/GP3A/P3A).

Tabel 1. Indikator Penilai Kuesioner

\begin{tabular}{lll}
\hline \multicolumn{1}{c}{ Aspek } & & \multicolumn{1}{c}{ Indikator } \\
\hline Sumber Daya Manusia & 1. & Kuantitas Pimpinan, staf dan tenaga OP \\
& 2. & Jumlah pimpinan, staf dan tenaga OP \\
\hline Institusi Pemerintah & 1. & Manajerial dalam pengelolaan irigasi \\
& 2. & Respon terhadap kerusakan saluran \\
3. & Keaktifan institusi \\
& 4. & IP3A/GP3A/P3A mempunyai fasilitas penunjang \\
\hline Pengelolaan & 1. & Pengembangan, pengelolaan irigasi dan unit regulator \\
& 2. & Pemerataan pembagian Air \\
3. & Pemeliharaan jaringan \\
4. & Kesesuaian AKNOP terhadap dana O\&P irigasi \\
& 5. & Tersedia manual operasi pintu dan operasi penangkap sedimen \\
& 6. & Ketersediaan buku pendukung \\
& 7. & Tata cara drainase \\
\hline
\end{tabular}


b. Kegiatan Focus Group Discussion (FGD) untuk P3A, GP3A, dan IP3A dan Mantri Pengairan/Juru.

c. Penelusuran jaringan irigasi untuk menilai fungsi bangunan, alat dan saluran irigasi.

Data sekunder didapat dari kajian pustaka dan arsip institusi daerah yaitu BAPPEDA, Kantor Kelurahan, dan Kantor Kecamatan, Pekerjaan Umum, Dinas Pertanian, Data lingkungan strategis. Data yang dikumpulkan antara lain:
a. Data kuesioner
b. Data teknis DI Batang Anai
c. Peta DI Batang Anai
d. Data luas daerah layanan
e. Data pola tanam

\section{Metode}

Hasil data yang diperoleh kemudian diolah dengan menggunakan beberapa analisis. Kerangka metodologis mencakup pengolahan data dengan integrasi Analytical Hierarchy Process (AHP) dalam Matriks SWOT.

\section{Metode AHP (Analytic Hierarchy Process)}

Prosedur penggunaan metode AHP dalam penelitian ini terdiri dari beberapa tahap, yaitu:

1. Menyusun hierarki dari permasalahan yang dihadapi setiap kriteria dapat memiliki sub kriteria di bawahnya dan setiap kriteria dapat memiliki nilai intensitas masing-masing (Gambar 1).

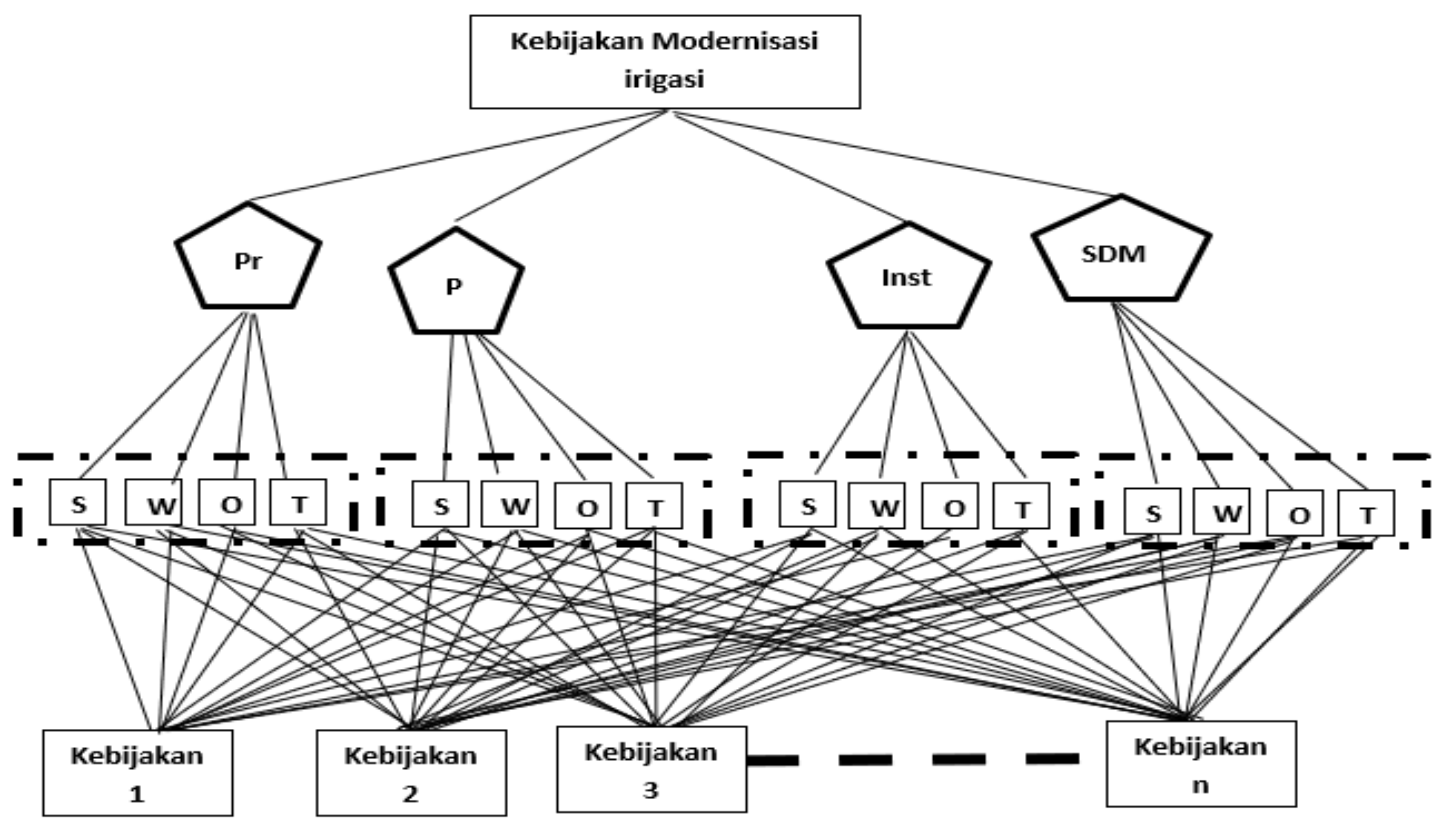

Gambar 1. Urutan Hierarki Sistem $(\mathrm{Pr}=$ Prasarana, $\mathrm{S}=$ Strengths, $\mathrm{P}=$ Pengelolaan, $\mathrm{W}=$ Weaknesses, Inst $=$ Institusi, $\mathrm{O}=$ Opportunities, $\mathrm{SDM}=$ Sumber Daya Manusia, $\mathrm{T}=$ Threats)

2. Setelah mengetahui permasalahan yang dihadapi, langkah selanjutnya adalah menentukan prioritas elemen. Langkah ini terbagi menjadi dua, yaitu membuat perbandingan berpasangan dan mengisi matriks perbandingan berpasangan (Tabel 2).
Tabel 2. Contoh matriks perbandingan berpasangan berdasarkan kuesioner

\begin{tabular}{ccccc}
\hline & Q1 & Q2 & Q3 & Qn \\
\hline Q1 & l & & & \\
Q2 & & 1 & & \\
Q3 & & & 1 & \\
Qn & & & & 1 \\
\hline
\end{tabular}


3. Pertimbangan-pertimbangan terhadap perbandingan berpasangan disintesis untuk memperoleh keseluruhan prioritas dengan langkah-langkah sebagai berikut:

a. Menjumlahkan nilai-nilai dari setiap kolom pada matriks.

b. Membagi setiap nilai dari kolom dengan total kolom yang bersangkutan untuk memperoleh normalisasi matriks.

c. Menjumlahkan nilai-nilai dari setiap matriks dan membaginya dengan jumlah elemen untuk mendapatkan nilai rata-rata.

d. Mengukur konsistensi dalam pembuat keputusan penting untuk mengetahui seberapa baik konsistensi yang ada, karena keputusan tidak boleh ditetapkan berdasarkan pertimbangan dengan konsistensi yang rendah. Karena dengan konsistensi yang rendah, pertimbangan akan tampak sebagai sesuatu yang acak dan tidak akurat. Konsistensi penting untuk mendapatkan hasil yang valid dalam dunia nyata.

AHP mengukur konsistensi pertimbangan dengan rasio konsistensi (consistency ratio). Nilai rasio konsistensi harus $10 \%$. Jika lebih dari rasio dari batas tersebut, maka nilai perbandingan matriks dilakukan kembali. Langkah-langkah menghitung nilai rasio konsistensi, yaitu:

a. Mengalikan nilai pada kolom pertama dengan prioritas relatif elemen pertama, nilai pada kolom kedua dengan prioritas relatif elemen kedua, dan seterusnya.

b. Menjumlahkan setiap baris.

c. Hasil dari penjumlahan baris dibagikan dengan elemen prioritas relatif yang bersangkutan.

d. Membagi hasil tersebut dengan banyak elemen yang ada, hasilnya

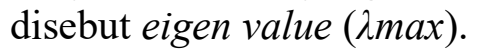

e. Menghitung indeks konsistensi (consistency index) dengan persamaan 1.

$\mathrm{CI}=\frac{\lambda \max -n}{n}$
Ket:

CI $=$ Consistency Index

$\lambda \max =$ Eigen Value

$\mathrm{n} \quad=$ Banyak elemen

1. Menghitung Consistency Ratio (CR) dengan persamaan 2 .

$\mathrm{CR}=\frac{\mathrm{CI}}{\mathrm{RC}}$

Ket:

$\mathrm{CR}=$ Consistency Ratio

$\mathrm{RC}=$ Random Consistency

$\mathrm{CI}=$ Consistency Index

Matriks random dengan skala penilaian 1 sampai 9 beserta pertentangan sebagai random consistency (RC). Berdasarkan perhitungan saaty, jika pertimbangan memilih secara acak dari skala $1 / 9,1 / 8, \ldots, 1,2, \ldots, 9$ akan diperoleh ratarata konsistensi untuk matriks yang berbeda seperti pada Tabel 3.

Tabel 3. Nilai rata-rata konsistensi

\begin{tabular}{cc}
\hline $\begin{array}{c}\text { Ukuran } \\
\text { Matriks }\end{array}$ & $\begin{array}{c}\text { Konsistensi acak } \\
\text { (Random Consistency) }\end{array}$ \\
\hline 1 & 0,0 \\
2 & 0,00 \\
3 & 0,58 \\
4 & 0,90 \\
5 & 1,12 \\
6 & 1,24 \\
7 & 1,32 \\
8 & 1,41 \\
9 & 1,45 \\
10 & 1,49 \\
\hline
\end{tabular}

\section{Analisis SWOT}

Analisis dilakukan berdasarkan posisi koordinat SWOT dari matriks IFAS (Internal Factors Analysis Summary) dan matriks EFAS (External Factors Analysis Summary). Matriks SWOT memiliki 4 kuadran berdasarkan pembagian S-W-O-T yang merupakan 4 set kemungkinan strategi (Sinambela, et al, 2018).

Setelah koordinat diketahui, dapat ditcntukan Daerah Irigasi Batang Anai masuk ke dalam Kuadran SWOT yang kemudian dikelompokkan berdasarkan tipologi strategi. Penentuan prioritas kegiatan untuk tiap pilar modernisasi irigasi didasarkan pada tipologi strategi dan faktor 
faktor dominan pada matriks IFAS dan EFAS.

a. Berdasarkan penilaian faktor SWOT pada masing-masing pilar dan pembobotan faktor SWOT menggunakan metode AHP dapat disusun matriks IFAS dan EFAS.

b. Pengambilan kebijakan dilakukan dengan melihat nilai pembobotan IFAS dan EFAS. Untuk kebijakan jangka pendek dipilih nilai bobot yang besar, sementara nilai bobot lainnya yang berada pada urutan ke 2 , ke 3 dan seterusnya dapat dijadikan sebagai kebijakan jangka panjang.

\section{HASIL DAN PEMBAHASAN}

Penentuan bobot dengan Metode Analytical Hierarchy Process

Seperti yang sudah dijelaskan sebelumnya, metode dalam penentuan kebijakan modernisasi irigasi ini salah satunya adalah dengan metode pembobotan guna mendapatkan prioritas dari tiap faktor SWOT yang ada, yaitu dengan metode AHP (Analytical Hierarchy Process). Tabel 4 adalah hasil perhitungan AHP dari pilar sumber daya manusia.

Tabel 4. Perhitungan metode AHP pilar sumber daya manusia

\begin{tabular}{ccccc}
\hline & \multicolumn{5}{c}{ SWOT } \\
\cline { 2 - 5 } & Strengths & Weaknesses & Opportunities & Threats \\
\hline \multirow{3}{*}{ Nilai Eigen } & 0,537 & 0,547 & 0,413 & 0,570 \\
& 0,099 & 0,109 & 0,245 & 0,333 \\
& 0,364 & 0,345 & 0,167 & 0,097 \\
\cline { 2 - 5 }$\lambda \max$ & & & 0,063 & \\
\cline { 2 - 5 } CI & 3,095 & 3,054 & 0,111 & 3,025 \\
\cline { 2 - 5 } CR & 0,048 & 0,027 & 5,443 & 0,012 \\
\cline { 2 - 5 } & 0,082 & 0,047 & 0,111 & 0,021 \\
\hline
\end{tabular}

Melalui Tabel 4 dapat diketahui bahwa nilai CR (Rasio Konsistensi) dari keempat hasil perhitungan AHP strengths, weaknesses, opportunities, dan threats memiliki nilai $<0,100$; sehingga dapat disimpulkan bahwa hasil preferensi responden adalah konsisten. Jika hasil CR tersebut sudah memiliki nilai 0,100 ; maka hasil perhitungan nilai eigen dari masingmasing variabel SWOT dapat digunakan sebagai bobot nilai dalam tabel penentuan IFAS dan EFAS. Sedangkan untuk hasil perhitungan AHP dari pilar institusi pemerintah disajikan dalam Tabel 5.

Tabel 5. Perhitungan metode AHP pilar institusi pemerintah

\begin{tabular}{ccccc} 
& \multicolumn{4}{c}{ SWOT } \\
\cline { 2 - 5 } & Strengths & Weaknesses & Opportunities & Threats \\
\cline { 2 - 5 } Nilai Eigen & 0,101 & 0,630 & 0,119 & 0,655 \\
& 0,152 & 0,161 & 0,088 & 0,055 \\
& 0,519 & 0,148 & 0,323 & 0,290 \\
$\lambda \max$ & 0,229 & 0,061 & 0,470 & 3,082 \\
CI & 4,220 & 4,242 & 4,193 & 0,041 \\
CR & 0,073 & 0,081 & 0,064 & 0,070 \\
\cline { 2 - 5 } & 0,082 & 0,090 & 0,072 &
\end{tabular}

Hasil Tabel 5 merupakan keseluruhan nilai CR (Rasio Konsistensi) hasil perhitungan AHP atas empat variabel
SWOT yang ada memiliki nilai $<0,100$ dapat dikatakan bahwa hasil preferensi responden adalah konsisten. Sehingga nilai 
eigen yang diperoleh dari perhitungan matriks dengan skala saaty dapat digunakan sebagai nilai bobot dalam tabel penentuan IFAS dan EFAS.

Terakhir adalah hasil perhitungan AHP pilar pengelolaan irigasi pada Tabel 6 . Melalui Tabel 6 dapat diketahui bahwa nilai CR (Rasio Konsistensi) dari keempat hasil perhitungan AHP strengths, weaknesses, opportunities, dan threats memiliki nilai $<0,100$ sehingga dapat disimpulkan bahwa hasil preferensi responden adalah konsisten. Jika hasil CR tersebut sudah memiliki nilai 0,100 , maka hasil perhitungan nilai eigen dari masing-masing variabel SWOT dapat digunakan sebagai bobot nilai dalam tabel penentuan IFAS dan EFAS.

Tabel 6. Perhitungan metode AHP pilar pengelolaan

\begin{tabular}{ccccc}
\hline & \multicolumn{4}{c}{ SWOT } \\
\hline & Strengths & Weaknesses & Opportunities & Threats \\
\cline { 2 - 5 } Nilai Eigen & 0,575 & 0,635 & 0,072 & 0,270 \\
& 0,241 & 0,287 & 0,649 & 0,594 \\
$\lambda \max$ & 0,123 & 0,078 & 0,279 & 0,052 \\
CI & 0,062 & & & 0,085 \\
CR & 4,175 & 3,096 & 3,066 & 4,256 \\
& 0,058 & 0,048 & 0,033 & 0,085 \\
& 0,065 & 0,082 & 0,057 & 0,095 \\
\hline
\end{tabular}

\section{Hasil Perhitungan Berdasarkan Pilar Modernisasi Irigasi}

Dari pengolahan data IKMI (Indeks Kesiapan Modernisasi Irigasi) yang dilakukan dengan menggunakan Excel diperoleh hasil dari kelima pilar modernisasi irigasi Daerah Irigasi Batang Anai yang disajikan dalam Tabel 7. Melalui hasil perhitungan nilai IKMI, dapat dilihat bahwa terdapat 3 pilar modernisasi irigasi yang memiliki nilai $<60$, yaitu sistem pengelolaan, institusi pemerintah, dan sumber daya manusia. Perbaikan yang dilakukan mungkin membutuhkan waktu 1-2 tahun agar dapat memenuhi predikat memadai guna dilakukannya modernisasi irigasi. Modernisasi yang dilakukan dan diterapkan di daerah irigasi ini nantinya direncanakan dan dapat disusun masukan kebijakankebijakannya sebagai acuan pola pencapaian modernisasi irigasi ke depan.

Tabel 7. Nilai IKMI daerah irigasi Batang Anai

\begin{tabular}{ccccc}
\hline & Bobot Upaya & Tingkat & Predikat & IKMI \\
\hline Ketersediaan Air & 20 & 80 & Memadai & 16,0 \\
Prasarana Irigasi & 25 & 90 & Memadai & 22,5 \\
Sistem pengelolaan & 20 & 41 & Kurang & 8,2 \\
Institusi Pengelola & 20 & 53 & Cukup & 10,5 \\
SDM & 15 & 53 & Cukup & 8,0 \\
\hline & & & Nilai IKMI & $\mathbf{6 5 , 2}$ \\
\hline
\end{tabular}

\section{Hasil Perhitungan Daerah Irigasi Batang Anai Berdasarkan Pilar Modernisasi}

Sebelumnya telah dijelaskan bahwa pilar modernisasi irigasi Batang Anai berada dalam predikat memadai. Terdapat tiga pilar yang memiliki nilai $<60$. Tabel 8 adalah tabel IFAS dan EFAS pilar Institusi pemerintah Daerah Irigasi Batang Anai. 
Tabel 8. Nilai IFAS institusi pemerintah daerah irigasi Batang Anai

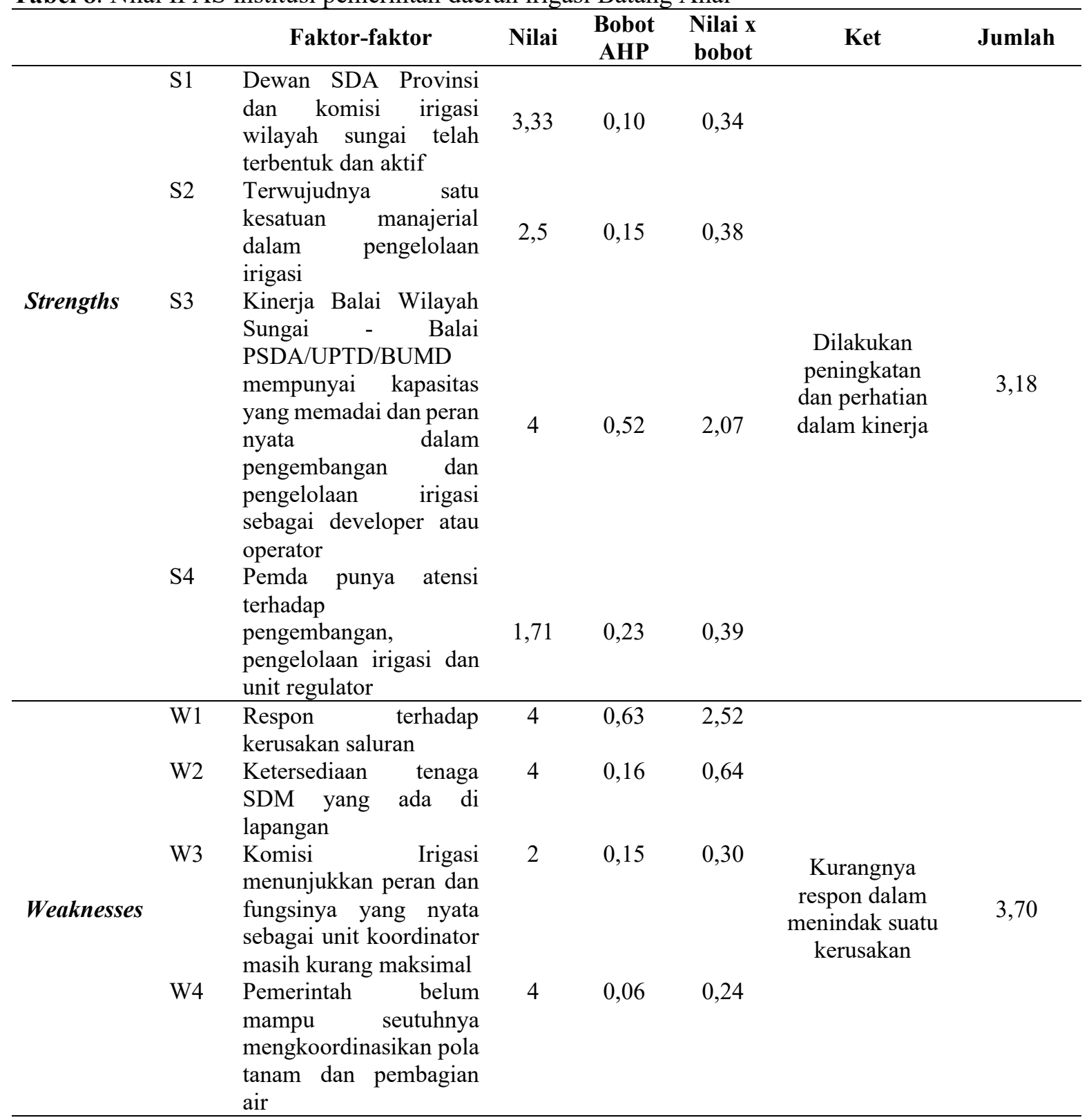

Berdasarkan Tabel 8, faktor kekuatan nilai terbesar dalam institusi pemerintah DI Batang Anai adalah Kinerja Balai Wilayah Sungai-Balai PSDA/UPTD/BUMD yang mempunyai kapasitas memadai dan peran nyata dalam pengembangan dan pengelolaan irigasi sebagai developer atau operator. Selain itu, adanya peran Pemda dalam regulasi dapat meningkatkan kekuatan institusi pemerintah yang sudah ada.
Sedangkan pada tabel weaknesses atau kelemahan, yang masih menjadi kendala adalah kurangnya respon dan kurangnya tenaga sumber daya alam yang ada di lapangan. Selanjutnya nilai opportunities serta threats pilar institusi pemerintah Daerah Irigasi Batang Anai tersaji pada Tabel 9. 
Tabel 9. Nilai EFAS institusi pemerintah Daerah Irigasi Batang Anai

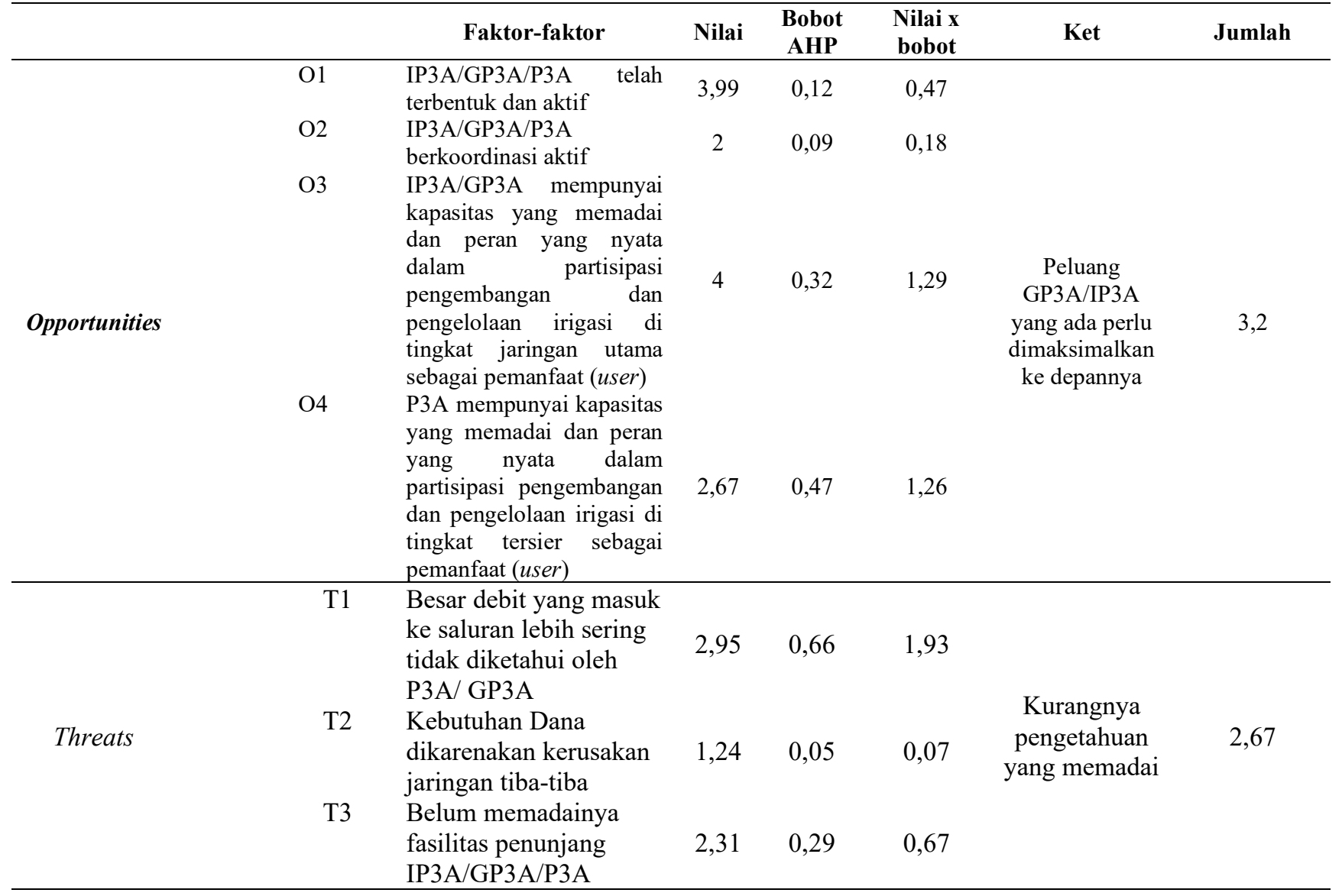

Seperti yang dapat disaksikan di Tabel 9, opportunities atau kekuatan pilar institusi pemerintah daerah irigasi Batang Anai, faktor yang paling dominan adalah IP3A/GP3A mempunyai kapasitas yang memadai dan peran yang nyata dalam partisipasi pengembangan dan pengelolaan irigasi di tingkat jaringan utama sebagai pemanfaat (user). Peluang yang ada ini ke depannya diharapkan dapat menjadi cara bagi petani untuk lebih memperhatikan lagi saluran irigasi dan pengelolaannya. Sedangkan untuk faktor ancaman dari luar, kurangnya pengetahuan petani akan kebutuhan debit serta kurangnya fasilitas yang memadai untuk menunjang kinerja petani dapat menjadi ancaman ke depan jika terus dibiarkan. Selanjutnya setelah dilakukan pembobotan dilakukan penilaian dengan menentukan letak pilar institusi pemerintah di kuadran yang telah tersedia.

Tabel 10. Pembobotan nilai institusi pemerintah Daerah Irigasi Batang Anai dengan AHP

\begin{tabular}{ccccccc} 
& Strengths & Weaknesses & S-W & Opportunities & Threats & O-T \\
\cline { 2 - 6 } $\begin{array}{c}\text { Sistem } \\
\text { Pengelolaan }\end{array}$ & 3,18 & 3,70 & $\mathbf{- 0 , 5 2}$ & 3,2 & 2,67 & $\mathbf{0 , 5 3}$ \\
(Batang Anai) & & & & & & \\
\hline
\end{tabular}

Melalui Tabel 10 kemudian dilakukan penempatan di titik koordinat untuk mengetahui letak kuadran dari nilai institusi pemerintah. Gambar 2 adalah titik koordinat yang didapat berdasarkan perhitungan sebelumnya. 


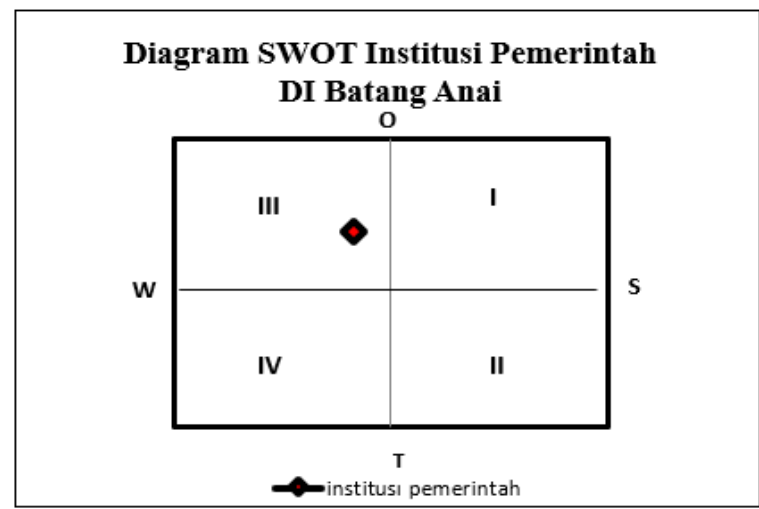

Gambar 2. Diagram analisis SWOT pilar Institusi Pemerintah Daerah Irigasi Batang Anai

Dari Gambar 2 dapat dilihat bahwa pilar SDM Daerah Irigasi Batang Anai berada pada kuadran III (Opportunities Weaknesses). Pada posisi kuadran ini pilar institusi pemerintah sebenarnya memiliki peluang yang besar, tetapi di lain pihak pilar ini memiliki kendala atau kelemahan yang berasal dari intern. Oleh karena itu, diperlukan peningkatan kemampuankemampuan guna menurunkan tingkat kelemahan intern yang ada, sehingga menimbulkan suatu kelebihan-kelebihan baru guna menjawab tantangan ke depan yang lebih keras nantinya. Akan lebih baik jika kegiatan institusi pemerintah tersebut difokuskan pada penyelesaian internal Daerah Irigasi Batang Anai terlebih dahulu, sehingga dapat mengatasi kelemahankelemahan yang muncul. Nilai strenghts serta weaknesses pilar sistem pengelolaan Daerah Irigasi Batang Anai tersaji pada Tabel 11.

Tabel 11. Penskoran IFAS sistem pengelolaan berdasarkan SWOT

\begin{tabular}{|c|c|c|c|c|c|c|c|}
\hline & & Faktor-faktor & Nilai & $\begin{array}{l}\text { Bobot } \\
\text { AHP }\end{array}$ & $\begin{array}{l}\text { Nilai } x \\
\text { bobot }\end{array}$ & Ket & Jumlah \\
\hline \multirow{4}{*}{ Strengths } & S1 & $\begin{array}{l}\text { Telah menerapkan aset } \\
\text { manajemen }\end{array}$ & 0 & 0,57 & 0,00 & \multirow{4}{*}{$\begin{array}{c}\text { Perlu } \\
\text { adanya } \\
\text { perhatian } \\
\text { lebih } \\
\text { ketersediaan } \\
\text { dan } \\
\text { penerapan } \\
\text { OP yang } \\
\text { ada }\end{array}$} & 0,33 \\
\hline & $\mathrm{S} 2$ & $\begin{array}{l}\text { Manual O\&P tersedia } \\
\text { dan dilaksanakan secara } \\
\text { konsisten }\end{array}$ & 0 & 0,24 & 0,00 & & \\
\hline & $\mathrm{S} 3$ & $\begin{array}{l}\text { Sistem pengelolaan air di } \\
\text { tingkat tersier tersedia } \\
\text { dan dilaksanakan secara } \\
\text { konsisten }\end{array}$ & 2,66 & 0,12 & 0,33 & & \\
\hline & $\mathrm{S} 4$ & $\begin{array}{l}\text { Tersedia manual operasi } \\
\text { pintu dan operasi } \\
\text { penangkap sedimen yang } \\
\text { dilaksanakan secara baik } \\
\text { dan benar }\end{array}$ & 0 & 0,06 & 0,00 & & \\
\hline \multirow{3}{*}{ Weaknesses } & W1 & $\begin{array}{l}\text { Dana O\&P irigasi belum } \\
\text { sesuai dengan AKNOP }\end{array}$ & 2 & 0,63 & 1,27 & \multirow{3}{*}{$\begin{array}{l}\text { Masih } \\
\text { lemahnya } \\
\text { teknologi }\end{array}$} & \multirow{3}{*}{1,58} \\
\hline & W1 & $\begin{array}{l}\text { Dana O\&P irigasi belum } \\
\text { sesuai dengan AKNOP }\end{array}$ & 2 & 0,63 & 1,27 & & \\
\hline & W1 & $\begin{array}{l}\text { Dana O\&P irigasi belum } \\
\text { sesuai dengan AKNOP }\end{array}$ & 2 & 0,63 & 1,27 & & \\
\hline
\end{tabular}

Faktor strengths atau kekuatan dari institusi pemerintah Daerah Irigasi Batang Anai, yaitu telah dilakukannya sistem pengelolaan air yang baik di tingkat tersier.
Dengan demikian dapat disimpulkan bahwa pengelolaan air yang dilakukan oleh para petani sudah menjadi faktor kekuatan yang dapat ditingkatkan. Selain itu, petani juga 
dapat lebih baik dalam usaha mengelola jaringan sekunder, bahkan membantu institusi dalam pengelolaan jaringan primer. Sedangkan kelemahan yang dihadapi oleh sistem pengelolaan Daerah Irigasi Batang Anai adalah belum ada kesesuaian dana operasi dan pemeliharaan yang dibutuhkan dengan angka kebutuhan nyata operasi dan pemeliharaan (AKNOP). Oleh karena itu, diperlukan pembahasan kembali, sehingga kinerja operasi dan pemeliharaan dapat lebih maksimal dan tidak terganggu oleh dana yang ada. Selanjutnya nilai opportunities serta threats pilar sistem pengelolaan Daerah Irigasi Batang Anai tersaji pada Tabel 12.

Tabel 12. Nilai EFAS sistem pengelolaan daerah irigasi Batang Anai

\begin{tabular}{|c|c|c|c|c|c|c|c|}
\hline & & Faktor-faktor & Nilai & $\begin{array}{l}\text { Bobot } \\
\text { AHP }\end{array}$ & $\begin{array}{l}\text { Nilai } x \\
\text { bobot }\end{array}$ & Ket & Jumlah \\
\hline \multirow{4}{*}{ Opportunities } & $\mathrm{O} 1$ & $\begin{array}{l}\text { Tata cara } \\
\text { pemeliharaan } \\
\text { jaringan } \\
\text { dilaksanakan } \\
\text { secara baik dan } \\
\text { benar }\end{array}$ & 0 & 0,07 & 0,00 & \multirow{4}{*}{$\begin{array}{l}\text { Masih } \\
\text { lemahnya } \\
\text { teknologi }\end{array}$} & \multirow{4}{*}{3,71} \\
\hline & $\mathrm{O} 2$ & $\begin{array}{l}\text { Tata cara drainase } \\
\text { dilaksanakan } \\
\text { secara baik dan } \\
\text { benar }\end{array}$ & 4 & 0,65 & 2,60 & & \\
\hline & $\mathrm{O} 3$ & $\begin{array}{l}\text { Tata cara operasi } \\
\text { pemeliharaan }\end{array}$ & & & & & \\
\hline & & $\begin{array}{lr}\text { pintu tersier } \\
\text { tersedia dan } \\
\text { dilaksanakan } \\
\text { dengan baik dan } \\
\text { benar }\end{array}$ & 4 & 0,28 & 1,12 & & \\
\hline \multirow{4}{*}{ Threats } & $\mathrm{T} 1$ & $\begin{array}{lr}\text { Perlu } & \text { dilakukan } \\
\text { revisi } & \text { manual } \\
\text { operasi } & \text { dan } \\
\text { pemeliharaan } & \text { agar } \\
\text { lebih sesuai }\end{array}$ & 0 & 0,27 & 0,00 & \multirow{4}{*}{$\begin{array}{c}\text { Kemerataan } \\
\text { air harus } \\
\text { ditingkatkan }\end{array}$} & \multirow{4}{*}{1,58} \\
\hline & $\mathrm{T} 2$ & $\begin{array}{l}\text { Kesulitan } \\
\text { distribusi air }\end{array}$ & 1,9 & 0,59 & 1,13 & & \\
\hline & $\mathrm{T} 3$ & $\begin{array}{l}\text { Pemerataan } \\
\text { pembagian air }\end{array}$ & 2,29 & 0,05 & 0,12 & & \\
\hline & $\mathrm{T} 4$ & $\begin{array}{l}\text { Ketersediaan } \\
\text { jaringan drainase }\end{array}$ & 4 & 0,08 & 0,34 & & \\
\hline
\end{tabular}

Diketahui dari Tabel 12, peluang atau opportunities, bahwa faktor penanganan drainase yang baik dan benar memiliki nilai yang besar pada sistem pengelolaan di daerah irigasi Batang Anai. Selain itu, untuk faktor ancaman atau threats diketahui bahwa kesulitan distribusi air menjadi suatu ancaman dari luar yang dapat menjadi kendala dalam upaya peningkatan kinerja pengelolaan guna menuju modernisasi irigasi ke depannya. Setelah dilakukan perhitungan, selanjutnya dilakukan pembobotan masing-masing faktor strengths, weaknesses, opportunities, dan threats lalu dilakukan penilaian dengan penempatan titik koordinat sistem pengelolaan pada kuadran yang ada. Berdasarkan Tabel 13 kemudian dilakukan penempatan di titik koordinat untuk mengetahui letak kuadran dari nilai sistem pengelolaan (Gambar 3). 
Tabel 13. Pembobotan nilai sistem pengelolaan Daerah Irigasi Batang Anai dengan AHP

\begin{tabular}{ccccccc}
\hline & Strengths & Weaknesses & S-W & Opportunities & Threats & O-T \\
\cline { 2 - 6 } $\begin{array}{c}\text { Sistem pengelolaan } \\
\text { (Batang Anai) }\end{array}$ & 0,33 & 1,58 & $\mathbf{- 1 , 2 6}$ & 3,71 & 1,59 & $\mathbf{2 , 1 3}$
\end{tabular}

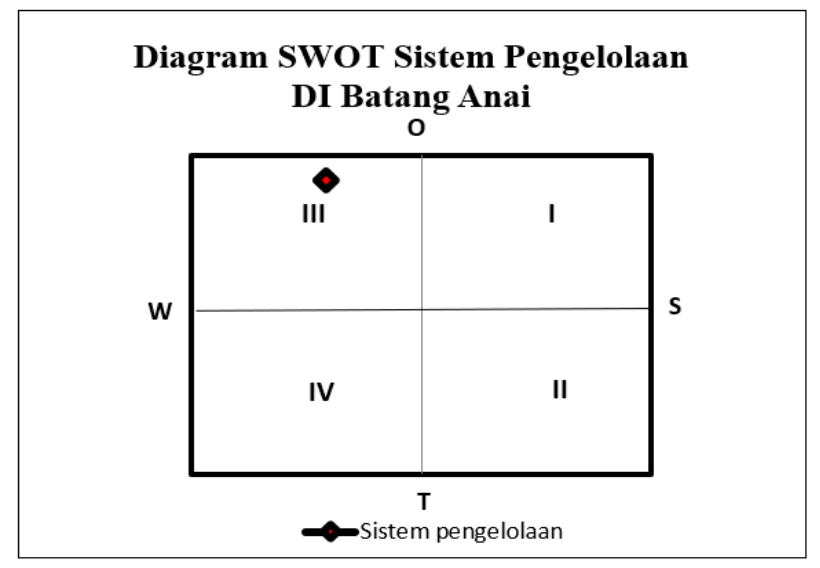

Gambar 3. Diagram analisis SWOT pilar sistem pengelolaan daerah irigasi Batang Anai

Sistem Pengelolaan Daerah Irigasi Batang Anai berada pada kuadran III (Opportunities - Weaknesses). Hal ini menunjukkan bahwa sistem pengelolaan Daerah Irigasi Batang Anai sudah dapat memanfaatkan peluang yang ada, tetapi adanya kelemahan internal menyebabkan pengenalan potensi-potensi kekuatan internal yang sebenarnya sudah bagus, tetapi belum digiatkan ke semua elemen pengelolaan yang berhubungan dengan irigasi. Sedangkan untuk pilar sumber daya manusia Daerah Irigasi Batang Anai disajikan dalam Tabel 14 .

Tabel 14. Penskoran IFAS Sistem SDM Daerah Irigasi Batang Anai berdasarkan SWOT

\begin{tabular}{|c|c|c|c|c|c|c|c|}
\hline & & Faktor-faktor & Nilai & $\begin{array}{l}\text { Bobot } \\
\text { AHP }\end{array}$ & $\begin{array}{l}\text { Nilai } x \\
\text { bobot }\end{array}$ & Ket & Jumlah \\
\hline \multirow[t]{4}{*}{ Strengths } & S1 & $\begin{array}{l}\text { Kuantitas Pimpinan, staf } \\
\text { dan tenaga OP memadai }\end{array}$ & 1,95 & 0,537 & 1,05 & \multirow{4}{*}{$\begin{array}{l}\text { Terpenuhinya } \\
\text { kuantitas } \\
\text { akan } \\
\text { meningkatkan } \\
\text { kinerja OP } \\
\text { lebih baik }\end{array}$} & \\
\hline & \multirow{3}{*}{$\mathrm{S} 3$} & $\begin{array}{l}\text { Jumlah pimpinan, staf dan } \\
\text { tenaga OP yang berstatus } \\
\text { pegawai negeri sipil } \\
>50 \% \text { dari pegawai yang } \\
\text { ada }\end{array}$ & 2,05 & 0,099 & 0,20 & & \\
\hline & & Jumlah pimpinan, staf dan & & & & & \\
\hline & & $\begin{array}{l}\text { tenaga OP yang } \\
\text { mempunyai jabatan } \\
\text { fungsional }>20 \% \text { dari } \\
\text { pegawai yang ada }\end{array}$ & 1 & 0,364 & 0,36 & & \\
\hline \multirow{5}{*}{ Weaknesses } & W1 & $\begin{array}{lr}\text { Kurangnya } & \text { kesadaran } \\
\text { petani P3A } & \text { dalam } \\
\text { membayar iuran } & \end{array}$ & 1,22 & 0,547 & 0,67 & \multirow{5}{*}{$\begin{array}{l}\text { Penyadaran } \\
\text { terhadap } \\
\text { petani lebih } \\
\text { ditingkatkan }\end{array}$} & \multirow{5}{*}{1,9} \\
\hline & W2 & Biaya OP yang besar & 3,05 & 0,109 & 0,33 & & \\
\hline & W3 & Rendahnya masyarakat & & & & & \\
\hline & & tani memiliki rasa & & & & & \\
\hline & & $\begin{array}{l}\text { tanggung jawab, apresiasi } \\
\text { terhadap irigasi dan } \\
\text { respon yang nyata dalam } \\
\text { partisipasi }\end{array}$ & 2,62 & 0,345 & 0,90 & & \\
\hline
\end{tabular}

Berdasarkan hasil pembobotan dengan AHP dan nilai dari kuesioner variabel Strengths (kekuatan) pada pilar sumber daya manusia Daerah Irigasi Batang Anai diketahui bahwa nilai prioritas atas faktorfaktor penyusun strengths terbesar adalah 
kuantitas pimpinan, staf dan tenaga operasi pemeliharaan memadai. Hal itu menjadi prioritas, karena jika tenaga operasi dan pemeliharaan yang ada sudah mencukupi, maka kinerja jaringan pun akan meningkat, terlepas apakah petugas operasi dan pemeliharaan tersebut sudah diangkat sebagai PNS atau tenaga fungsional.
Sedangkan untuk kelemahannya, sumber daya manusia memiliki rasa tanggung jawab, apresiasi terhadap irigasi, dan respon nyata dalam partisipasi yang masih rendah. Opportunities serta threats pilar sistem pengelolaan Daerah Irigasi Batang Anai tersaji pada Tabel 15 .

Tabel 15. Penskoran EFAS Sistem SDM Daerah Irigasi Batang Anai berdasarkan SWOT

\begin{tabular}{|c|c|c|c|c|c|c|c|}
\hline & & Faktor faktor & Nilai & $\begin{array}{l}\text { Bobot } \\
\text { AHP }\end{array}$ & $\begin{array}{l}\text { Nilai } x \\
\text { bobot }\end{array}$ & Ket & Jumlah \\
\hline \multirow{5}{*}{ Opportunities } & O1 & $\begin{array}{l}\text { Jumlah pimpinan, staf dan } \\
\text { tenaga operasi dan } \\
\text { pemeliharaan } \quad \text { yang } \\
\text { mempunyai Sertifikat } \\
\text { keahlian O\&P }>20 \% \text { dari } \\
\text { pegawai yang ada }\end{array}$ & 0,75 & 0,41 & 0,31 & \multirow{5}{*}{$\begin{array}{l}\text { Banyaknya } \\
\text { pegawai } \\
\text { terlatih dapat } \\
\text { menjadi } \\
\text { peluang yang } \\
\text { baik }\end{array}$} & \multirow{5}{*}{1,24} \\
\hline & $\mathrm{O} 2$ & $\begin{array}{l}\text { Jumlah pimpinan, staf dan } \\
\text { tenaga OP yang telah } \\
\text { mengikuti pelatihan O\&P }> \\
20 \% \text { dari pegawai yang ada }\end{array}$ & 2,45 & 0,24 & 0,60 & & \\
\hline & $\mathrm{O} 3$ & $\begin{array}{l}\text { Jumlah P3A yang telah } \\
\text { mendapat pelatihan }>40 \% \\
\text { dari P3A yang ada }\end{array}$ & 0 & 0,17 & 0,00 & & \\
\hline & $\mathrm{O} 4$ & $\begin{array}{l}\text { Produktivitas padi di atas } 5 \\
\text { ton/ha }\end{array}$ & 1,9 & 0,06 & 0,12 & & \\
\hline & O5 & $\begin{array}{l}\text { Adanya dana bantuan lain } \\
\text { selain dari P3A }\end{array}$ & 1,9 & 0,11 & 0,21 & & \\
\hline \multirow{3}{*}{ Threats } & T1 & $\begin{array}{lr}\text { Adanya } & \text { keinginan } \\
\text { memiliki } & \text { lahan } \\
\text { menentukan } & \text { budidayanya } \\
\text { sendiri } & \end{array}$ & 2,48 & 0,570 & 1,41 & \multirow{3}{*}{$\begin{array}{c}\text { Perlu adanya } \\
\text { pengawasan } \\
\text { lebih di } \\
\text { lapangan }\end{array}$} & \multirow{3}{*}{1,98} \\
\hline & $\mathrm{T} 2$ & $\begin{array}{l}\text { Sebagian besar petani } \\
\text { memiliki lahan }<2 \text { ha }\end{array}$ & 1,38 & 0,333 & 0,46 & & \\
\hline & T3 & Alih fungsi lahan & 1,14 & 0,097 & 0,11 & & \\
\hline
\end{tabular}

Melalui Tabel 15 diketahui bahwa kekuatan sumber daya manusia Daerah Irigasi Batang Anai adalah jumlah pimpinan, staf, serta tenaga operasi dan pemeliharaan (OP) yang telah mengikuti pelatihan O\&P > $20 \%$ dari pegawai yang ada. Ini merupakan hal yang baik, karena dengan banyaknya pelatihan yang diberikan nantinya para staf dapat menularkannya ke para petani sehingga pengetahuan yang ada dapat juga diaplikasikan di lapangan oleh para petani. Sedangkan diketahui bahwa adanya keinginan pemilik lahan menentukan budidayanya sendiri dapat menjadi ancaman yang nantinya dapat merusak pola tanam yang telah ditentukan oleh pemerintah. Setelah pemberian skor kuesioner dengan mengkualifikasikan berdasarkan kekuatan, peluang, ancaman, dan kelemahan selanjutnya diolah hingga didapatkan nilai pada Tabel 16. Nilai pembobotan dengan menggunakan metode AHP pada Tabel 16 selanjutnya diolah ke dalam bentuk kuadran SWOT untuk mengetahui letak titik pilar sumber daya manusia Daerah Irigasi Batang Anai (Gambar 4). 
Tabel 16. Pembobotan nilai sumber daya manusia Daerah Irigasi Batang Anai dengan AHP

\begin{tabular}{lrlllll} 
(Batang Anai) & 1,61 & 1,90 & $\mathbf{- 0 , 2 9}$ & 1,24 & 1,98 & $\mathbf{- 0 , 7 4}$ \\
\cline { 2 - 7 }
\end{tabular}

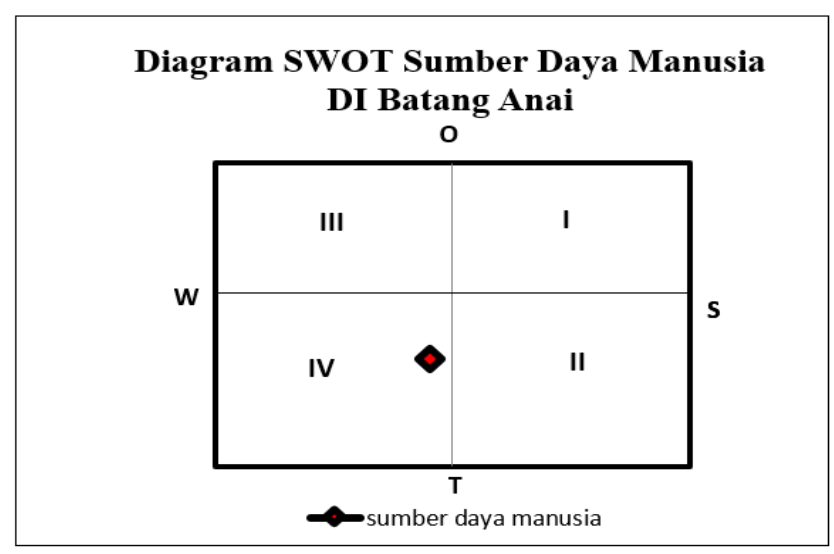

Gambar 4. Diagram analisis SWOT pilar sumber daya manusia DI Batang Anai

Pada Gambar 4 terlihat bahwa letak pilar sumber daya manusia Daerah Irigasi Batang Anai berada pada kuadran IV (Weaknesses - Threats). Sebenarnya pilar ini berada dalam posisi yang sulit karena adanya kelemahan internal juga berbagai ancaman dari luar yang mengakibatkan sumber daya manusia Daerah Irigasi Batang Anai tidak mampu menangkap berbagai kesempatan yang datang serta kekuatan yang ada juga tidak dimaksimalkan.

\section{Penentuan Kebijakan Modernisasi Irigasi} Berdasarkan penilaian faktor SWOT pada Daerah Irigasi Batang Anai dan pembobotan faktor SWOT menggunakan metode AHP, dapat disusun diagram secara keseluruhan. Gambar 5 adalah keseluruhan penempatan pilar modernisasi irigasi Daerah Irigasi Batang Anai ke dalam koordinat SWOT.

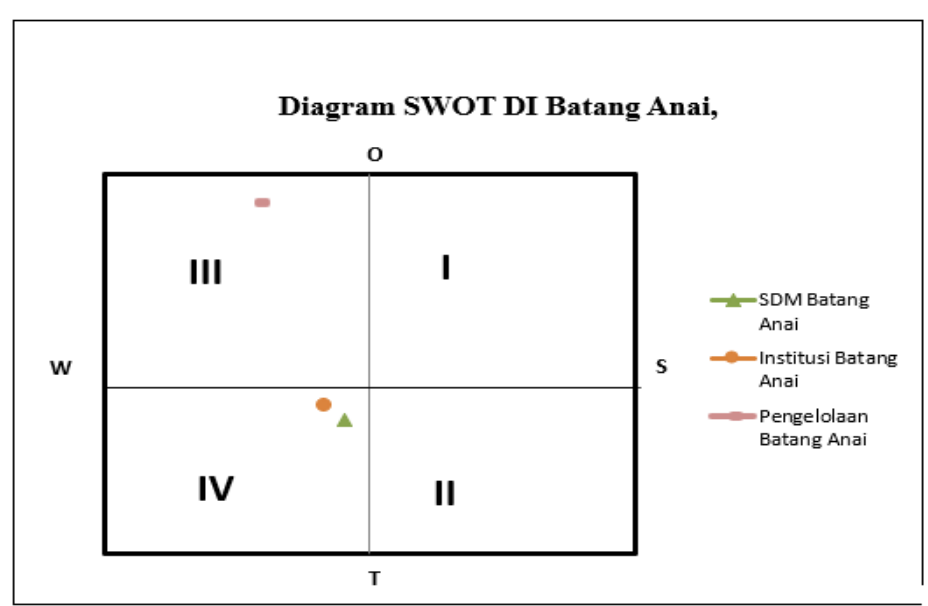

Gambar 5. Diagram analisis SWOT keseluruhan pilar

Dari Gambar 5 dapat diketahui bahwa letak koordinat merata berada pada kuadran III dan IV, yaitu turn around dan defensive. Selanjutnya dilakukan penentuan strategi yang nantinya menjadi bahan untuk menentukan kebijakan yang bisa diberikan sebagai cara untuk meningkatkan kinerja masing-masing pilar. 
Tabel 17. Penentuan strategi kebijakan modernisasi irigasi SWOT

\begin{tabular}{|c|c|c|c|}
\hline Tipologi & Kondisi & Pilar modernisasi irigasi & Strategi \\
\hline $\mathrm{W}-\mathrm{O}$ & $\begin{array}{l}\text { Pilar modernisasi di daerah irigasi tersebut } \\
\text { menghadapi peluang yang besar, tetapi di pihak } \\
\text { lain menghadapi beberapa kendala/kelemahan } \\
\text { internal }\end{array}$ & $\begin{array}{l}\text { 1. Institusi pemerintah } \\
\text { 2. Sistem pengelolaan }\end{array}$ & Turn Around \\
\hline W-T & $\begin{array}{l}\text { Situasi sangat tidak menguntungkan, irigasi di } \\
\text { daerah tersebut menghadapi berbagai ancaman } \\
\text { dan kelemahan internal. }\end{array}$ & 1. SDM & Defensive \\
\hline
\end{tabular}

\section{Berdasarkan Tabel 17 dibuat Umum.}

rekomendasi prioritas kegiatan untuk masing-masing pilar modernisasi berdasarkan daerah irigasinya masingmasing. Jenis kebijakan yang direkomendasikan atau dipilih berdasarkan kriteria dari masing-masing pilar modernisasi irigasi pada indeks kesiapan modernisasi irigasi dalam buku Pedoman Modernisasi Irigasi Kementerian Pekerjaan

\section{Topologi W-O dan W-T}

Penentuan kebijakan berdasarkan letak pilar modernisasi pada kuadran II (Weaknesses - Opportunities) dijelaskan pada Tabel 18. Sedangkan Tabel 19 menunjukkan penentuan kebijakan berdasarkan letak pilar modernisasi pada kuadran IV (Weaknesses - Threats).

Tabel 18. Kebijakan Modernisasi Irigasi dengan Topologi W-O

\begin{tabular}{|c|c|c|}
\hline \multirow{2}{*}{$\begin{array}{c}\text { Pilar } \\
\text { modernisasi irigasi }\end{array}$} & \multicolumn{2}{|c|}{ Kebijakan modernisasi irigasi } \\
\hline & Jangka Pendek & Jangka Panjang \\
\hline $\begin{array}{l}\text { Institusi pemerintah } \\
\text { (Batang Anai) }\end{array}$ & $\begin{array}{l}\text { 1. Pembentukan dan Peningkatan kinerja } \\
\text { dewan SDA atau komisi irigasi agar } \\
\text { lebih aktif } \\
\text { 2. Peningkatan respon jika terjadi } \\
\text { kerusakan saluran oleh pemerintah } \\
\text { 3. Peningkatan koordinasi aktif bagi } \\
\text { IP3A / GP3A / P3A } \\
\text { 4. Peningkatan pengetahuan bagi petani } \\
\text { mengenai besar debit, atau kebutuhan } \\
\text { debit di saluran dan petak-petak sawah } \\
\text { masing-masing petani }\end{array}$ & $\begin{array}{l}\text { 1. Mewujudkan suatu kesatuan manajerial dan } \\
\text { pengelolaan irigasi } \\
\text { 2. Peningkatan kinerja PEMDA dalam peran } \\
\text { yang nyata dalam pengembangan dan } \\
\text { pengelolaan irigasi sebagai unit regulator } \\
\text { 3. Peningkatan jumlah tenaga SDM di } \\
\text { lapangan } \\
\text { 4. Peningkatan pembentukan IP3A// } \\
\text { GP3A/P3A dan pengaktifan organisasi } \\
\text { tersebut } \\
\text { 5. Peningkatan fasilitas penunjang bagi IP3A/ } \\
\text { GP3A/P3A }\end{array}$ \\
\hline $\begin{array}{l}\text { Sistem pengelolaan } \\
\text { (Batang Anai) }\end{array}$ & $\begin{array}{l}\text { 1. Peningkatan penerapan aset } \\
\text { manajemen } \\
\text { 2. Peningkatan ketersediaan manual OP } \\
\text { dan dilaksanakan secara konsisten } \\
\text { 3. Pengadaan manual operasi pintu dan } \\
\text { operasi penangkap sedimen yang } \\
\text { dilaksanakan secara baik dan benar } \\
\text { 4. Peningkatan kesesuaian dana OP } \\
\text { dengan AKNOP } \\
\text { 5. Peningkatan tata cara pemeliharaan } \\
\text { jaringan dilaksanakan secara baik dan } \\
\text { benar }\end{array}$ & $\begin{array}{l}\text { 1. Peningkatan ketersediaan sistem } \\
\text { pengelolaan air di tingkat tersier dan } \\
\text { dilaksanakan secara konsisten } \\
\text { 2. Pengadaan ketersediaan dokumen } \\
\text { pendukung: buku DI, BCP, peta, ikhtisar, } \\
\text { skema irigasi dan peta petak } \\
\text { 3. Peningkatan pengelolaan dan tata cara OP } \\
\text { pintu tersier secara baik dan benar } \\
\text { 4. Peningkatan kemerataan pembagian air } \\
\text { 5. Peningkatan pengadaan dan tata cara } \\
\text { jaringan }\end{array}$ \\
\hline
\end{tabular}

Tabel 19. Kebijakan Modernisasi Irigasi dengan Topologi W-T

\begin{tabular}{|c|c|c|c|}
\hline \multirow{2}{*}{$\begin{array}{c}\text { Pilar } \\
\text { modernisasi irigasi }\end{array}$} & \multicolumn{3}{|c|}{ Kebijakan modernisasi irigasi } \\
\hline & & Jangka Pendek & Jangka Panjang \\
\hline $\begin{array}{c}\text { SDM } \\
\text { (Batang Anai) }\end{array}$ & 2. & $\begin{array}{l}\text { Peningkatan jumlah pimpinan, staf, dan } \\
\text { tenaga OP yang berstatus PNS menjadi } \\
>50 \% \text { dari pegawai yang ada } \\
\text { Peningkatan rasa memiliki, rasa tanggung } \\
\text { jawab, apresiasi terhadap irigasi dan } \\
\text { respon yang nyata dalam partisipasi } \\
\text { irigasi }\end{array}$ & $\begin{array}{l}\text { 1. Peningkatan jumlah pimpinan, staf dan } \\
\text { tenaga OP yang memiliki jabatan fungsional } \\
>20 \% \text { dari pegawai yang ada } \\
\text { 2. Peningkatan jumlah petani yang mampu } \\
\text { membayar iuran } \mathrm{P} 3 \mathrm{~A}>60 \% \\
\text { 3. Peningkatan produktivitas padi di atas } 5 \\
\text { ton/ha }\end{array}$ \\
\hline
\end{tabular}


3. Peningkatan jumlah P3A yang telah mendapatkan pelatihan menjadi $>40 \%$ dari P3A yang ada

4. Sosialisasi dan pemberian saksi yang tegas dalam penentuan pola tanam bagi petani
4. Peningkatan jumlah petani yang memiliki lahan di atas 2 ha menjadi $>20 \%$ dari jumlah petani yang ada

\section{KESIMPULAN DAN SARAN}

\section{Kesimpulan}

Pada penelitian ini diperoleh strategi turn around kuadran III (Opportunities Weaknesses) SWOT, yaitu: sistem pengelolaan Daerah Irigasi Batang Anai pada pilar tersebut memiliki kelemahan internal, tetapi di sisi lain terdapat peluang yang sangat besar. Selain itu, diperoleh strategi defensive kuadran IV (Weaknesses Threats) SWOT, yaitu: institusi pemerintah di dalam Daerah Irigasi Batang Anai dan sumber daya manusia pemeliharaan yang ada juga harus disesuaikan dengan angka kebutuhan nyata operasi dan pemeliharaan.

\section{Saran}

Diharapkan artikel ini dapat meningkatkan pengetahuan petani tentang besar debit yang mengalir dari hulu hingga hilir agar petani lebih mandiri dalam menghadapi persoalan irigasi nantinya. Selain itu, artikel ini diharapkan dapat menjadi referensi bagi pemerintah khususnya PU dalam pengambilan kebijakan modernisasi irigasi ke depannya. Pemerintah dan petani perlu lebih berperan nyata dalam pengembangan dan pengelolaan irigasi, baik dari primer, sekunder maupun tersier. Pilar tersebut memiliki kelemahan internal dan ancaman eksternal yang menjadikan pilar dalam posisi ini menjadi sangat tidak menguntungkan. Kebijakan modernisasi irigasi Batang Anai harus dimulai dengan ketepatan dan kecepatan respon terhadap kerusakan saluran sesuai dengan operasi dan pemeliharaan.

\section{UCAPAN TERIMA KASIH}

Ucapan terima kasih disampaikan kepada Kementerian PUPR dan Dirjen Bidang Sumberdaya Air yang memberikan kesempatan dan sarana untuk melakukan penelitian ini, serta kepada Jurusan Teknik Pertanian dan Biosistem Fakultas Teknologi Pertanian UGM.

\section{DAFTAR REFERENSI}

Angguniko, B. Y., \& Hidayah, S. (2017). Rancangan Unit Pengelola Irigasi Modern di Indonesia. Jurnal Irigasi, 12(1), 23-36.

Arif, S.S., \& Prabowo, A., Sastrohardjono, S., Sukarno, I., \& Sidharti, T.S. (2014). Pokok-pokok Modernisasi Irigasi Indonesia. Jakarta: Direktorat Jenderal Sumber Daya Air, Kementerian Pekerjaan Umum.

Direktorat Irigasi dan Rawa. (2015). Rencana Strategis Direktorat Irigasi dan Rawa 2015-2019. Jakarta: Direktorat Irigasi dan Rawa, Direktorat Jenderal Sumber Daya Air, Kementerian Pekerjaan Umum dan Perumahan Rakyat.

FAO. (1997). Summary Report: Modernization of Irrigation Scheme: Past Experiences and Future Option. Rome, Italy: Food and Agriculture Organization, United Nations.

Hakim, A., Suriadi, A., \& Masruri. (2012). Tingkat Kesiapan Masyarakat Petani Terhadap Rencana Modernisasi Irigasi (studi kasus di Daerah Irigasi Barugbug, Jawa Barat). Jurnal Sosial Ekonomi Pekerjaan Umum, 4(2), 6778.

Head, B., \& Cammerman, N. (2010). The Water-Energy Nexus: A Challenge for Knowledge and Policy. Urban Water 
Security Research Alliance, (Technical Report No. 39).

Martief, M. M., \& Krisbandono, A. (2015). Modernisasi, Peningkatan Jaringan, atau Rehabilitasi Irigasi. Jakarta, Indonesia: Badan Penelitian dan Pengembangan, Kementerian Pekerjaan Umum dan Perumahan Rakyat.

Murtiningrum, Ristiana, S., \& Wahyuningtyas, Y. (2014). Penyusunan Strategi Pemberdayaan GP3A untuk Peningkatan Partisipasi Pada O\&P Jaringan Utama Sistem Irigasi. Jurnal Irigasi, 9(2), 115-125.

Nam, V. H. (2016). Research and Proposal on the Irrigation Modernization Framework in Red River Delta, Vietnam. Dalam International Conference on the Mekong, Salween and Red Rivers: Sharing Knowledge and Perspectives Across Borders (hlm. 429-455). Chulalongkorn University.

Prasetijo, H. (2010). Studi Pemberdayaan Lembaga Pengelola Jaringan Irigasi di Tingkat Desa. Jurnal Teknik
Pengairan, 1(1), 1-12.

Priyonugroho, A. (2014). Analisis Kebutuhan Air Irigasi (Studi Kasus Pada Daerah Irigasi Sungai Air Keban Daerah Kabupaten Empat Lawang). Jurnal Teknik Sipil dan Lingkungan, 2(3), 457-470.

Rasul, G., \& Sharma, B. (2016). The nexus approach to water-energy-food security: an option for adaptation to climate change. Climate Policy, 16(6), 682-702.

Sinambela, Y., Darnianti., \& Panjaitan, N. (2018). Analisis Strategi Pemasaran CV Karunia Makmur Persada (KMP) dan Metode SWOT. Juitech, 02(02), $56-66$.

Wiyono, A., Wachyuni, S., \& Rismanto. (2013). Kajian Peran Serta Petani Dalam Operasi dan Pemeliharaan Infrastruktur Jaringan Irigasi Dengan Pendekatan Theory of Planned Behaviour (TPB) (Studi Kasus : Daerah Irigasi Cirasea Kabupaten Bandung, Jawa Barat). Jurnal Sosioteknologi, 12(30), 502-525. 